\title{
Rheumatic Heart Disease and Its Association with H. pylori Infection
}

\author{
Ghadeer Turki Aloutaibi ${ }^{1}$, Abdulrahman L. Al-Malki ${ }^{1,2,3 *}$, \\ Maha J. Balgoon ${ }^{1}$, Saud A. Bahaidarah ${ }^{4}$ and Said Salama Moselhy ${ }^{5}$ \\ ${ }^{1}$ Department of Biochemistry, Faculty of Science, King Abdulaziz University, (KAU), Jeddah, Saudi Arabia. \\ ${ }^{2}$ Bioactive Natural Products Research Group, KAU, Jeddah, Saudi Arabia. \\ ${ }^{3}$ Experimental Biochemistry Unit, King Fahd Medical Research Center, KAU, Jeddah, Saudi Arabia. \\ ${ }^{4}$ Department of Pediatric, Faculty of Medicine, King Abdulaziz University, (KAU), Jeddah, Saudi Arabia. \\ ${ }^{5}$ Department of Biochemistry, Faculty of Science, Ain Shams University, Cairo, Egypt.
}

\begin{abstract}
Acute rheumatic fever (ARF) triggered by Group A Streptococcus bacterium due to post-infectious and non-supportive pharyngeal infection. Depending on certain conditions, such as genetic predisposition to the disease, the prevalence of various cases of rheumatism and socioeconomic status in different regions, ARF can have different clinical manifestations. The disease typically manifested by one or more acute episodes, whereas $\mathbf{3 0 - 5 0 \%}$ of all repeated ARF status can result in chronic rheumatic heart disease (RHD) with gradual and irreversible heart valve damage and also have been found to be correlated with a raised risk of myocardial infarction (MI), cardiovascular disease (CVD) and dyslipidemia. The RHD is the only long-term consequence of ARF and the most serious. The development to chronic RHD is determined by many factors, most notably the frequent episodes of rheumatic fever (RF). The RHD is known socially and economically as being the most frequent heart disease in vulnerable populations. $H$. pylori infection has been proposed to be involved RHD greater than that of the normal healthy people. $H$. pylori can be considered as one of the probable risk factor for RHD. It was concluded that, patients with $H$. pylori should be advised to follow up in cardiology clinics to avoid any complications.
\end{abstract}

Keywords: H. pylori, Streptococcal A, Rheumatic heart disease

*Correspondence: alalmalki@kau.edu.sa
(Received: January 18, 2021; accepted: May 10, 2021)
Citation: Aloutaibi GT, Al-Malki AL, Balgoon MJ, Bahaidarah SA, Moselhy SS. Rheumatic Heart Disease and Its Association
with H. pylori infection. J Pure Appl Microbiol. 2021;15(2):580-586. doi: 10.22207/JPAM.15.2.42
@ The Author(s) 2021. Open Access. This article is distributed under the terms of the Creative Commons Attribution 4.0 International License which
permits unrestricted use, sharing, distribution, and reproduction in any medium, provided you give appropriate credit to the original author(s) and
the source, provide a link to the Creative Commons license, and indicate if changes were made. 


\section{INTRODUCTION}

Acute rheumatic fever (ARF) is triggered by an immune reaction to Group A Streptococcus pharyngeal infection ${ }^{1}$. Depending on certain conditions, such as genetic predisposition and socioeconomic status, ARF can have different clinical manifestations ${ }^{2}$. The disease is typically manifested by one or more acute episodes, whereas $30-50 \%$ of all repeated ARF status can result in chronic rheumatic heart disease (RHD) with gradual and irreversible heart valve damage ${ }^{3-4}$. The development of chronic RHD is determined by many factors, most notably the frequent rheumatic fever episodes. RHD is known socially and economically as the most frequent heart disease in vulnerable populations $s^{1-5}$. RHD has become rare in developed countries, but it is still a public health problem in developing countries ${ }^{6}$. It is estimated that more than 282,000 new RHD cases and 233,000 RHD-related deaths are reported annually ${ }^{7}$. Over the past 25 years, the association between infection caused by pathogen and autoimmunity has progressively been identified ${ }^{8}$.

\section{Carditis}

The most intense RF manifestation develops within three weeks of GAS infection. It is pericarditis: Endocarditis usually present, mitral regurgitation is the most common pathology in $\mathrm{RF}$, manifested by an apical systolic murmur. In about $50 \%$ of cases, it may be accompanied by basal diastolic murmur due to aortic regurgitation ${ }^{8}$. Myocardial disease with atrioventricular conduction disturbances or congestive heart failure and rare pericarditis (5\%). Cardiac involvement seen in about $50 \%$ of 17 patients with ARF and about $70 \%$ using echocardiography. Doppler echocardiography should use as an adjunct technique to confirm clinical auscultatory findings; however, it should not be used as a major or minor endpoint to diagnosing carditis associated with ARF $^{9}$.

\section{Epidemiology}

The incidence of ARF and its long-term squeal, RHD, is low in high-income countries, mainly due to the region's improved socioeconomic situation, population and effective infection control with Penicillin Benzathine G (BPG) (9). However, RHD remains a significant concern in a few developed countries, such as Australia and New Zealand, especially among indigenous populations, such as Aboriginal Australians, mainly due to inadequate access to health care resources ${ }^{10}$. RHD remains a major public health problem, in low and middle-income countries due to overcrowding, poor hygiene and poor adherence to secondary prophylaxis ${ }^{11} \mathrm{An}$ interesting example is Brazil, which has experienced an impressive reduction in the incidence and mortality of $\mathrm{RHD}^{14}$, while its prevalence ( 1 to 7 cases / 1000) remains high when compared to developed countries (0.1-0.4 cases / 1000 schoolchildren) ${ }^{13}$.

\section{Risk factors}

Age and sex

The incidence of early ARF cases is higher in children aged 5 to 14 years, although the first episodes occur in young children, with cases of ARF being reported in children aged 2 to 3 years ${ }^{15}$. The early episodes can also occur in adolescents and the elderly in some cases $>30$ years of age are rare. In contrast, recurring episodes often affect slightly older children, adolescents and young adults, are rarely to be seen beyond 35 to 40 years of age. RHD is a chronic disease, although it occurs in children. Their prevalence is highest in adulthood, usually between 25 and 45 years of age (16).In most populations, ARF is equally common amongst men and women. However, RHD occurs more frequently in women, with a relative risk of 1.6 to 2.0 compared to men. Besides, these gender differences may be more significant in adolescents and adults than in children ${ }^{17}$. RHD during pregnancy is recognizably increasing. Indeed, data from South Africa and Senegal suggests that rheumatoid disease is one of the leading causes of indirect obstetric deaths, which in turn accounts for $25 \%$ of all maternal deaths in developing countries ${ }^{18}$. This effect is related to the worsening of a pre-existing disease due to hemodynamic changes during pregnancy rather than increased sensitivity to ARF or RHD due to pregnancy.

\section{Environmental factors}

Environmental factors can explain the vast majority of the differences in risk between populations worldwide. The relative contribution of each of these individual risks is difficult to clarify as many of them overlap, and most of it linked to poverty and economic disadvantage ${ }^{19}$. Household crowding is also a very plausible risk 
factor for ARF, as it increases the number of useful breeds for infections in the household. Household congestion can manifest itself in several ways, including high household occupancy, lack of rooms or space for the number of residents and sharing of beds. In New Zealand, household overload has been identified as a risk factor for other bacterial diseases, including meningococcal disease, pneumonia in children and tuberculosis ${ }^{20}$. Current data clearly show a connection between ARF and RHD and household overload ${ }^{21}$.

\section{Molecular Mimicry}

Molecular mimicry in ARF occurs due to alpha-helical protein structures found in $M$ protein and $\mathrm{N}$-acetyl-beta-D glucosamine, the carbohydrate antigen of $S$. pyogenes cross-reaction with cardiac myosin, myocardium, and valves. Cross-reactive antibodies cause upregulation of vascular cells adhesion molecule 1 , which results in the adhesion of CD4 + T cells to the endothelium, and then the cells enter the valve ${ }^{22}$. Inflammation occurs when T cells release $\gamma$-IFN due to TH1 response, leading to neovascularization and other $\mathrm{T}$ cell recruitment ${ }^{23}$. $\mathrm{T}$ cells infiltrate heart valves and cause scarring due to inflammation of the endothelium surrounding the valve ${ }^{24}$. Also, autoantibodies against collagen that are not crossreactive may form because of the release of collagen from damaged valve during RHD or to responses to collagen bound in vitro by certain serotypes of streptococci.

\section{Microbiological Characteristics \\ Phenotypic characteristics}

The structure of $H$. pylori as shown in fig (2), was originally thought to be a species belonging to the genus Campylobacter and was first named Campylobacter pyloridis, which was later corrected to Campylobacter pylori(C. pylori $)^{24}$. Members of the genus Helicobacter described in 1989. They colonize the stomach and intestines of man and certain animal species (fig 3). Helicobacter is a gram-negative, microaerophilic

\section{The structure of Helicobacter}

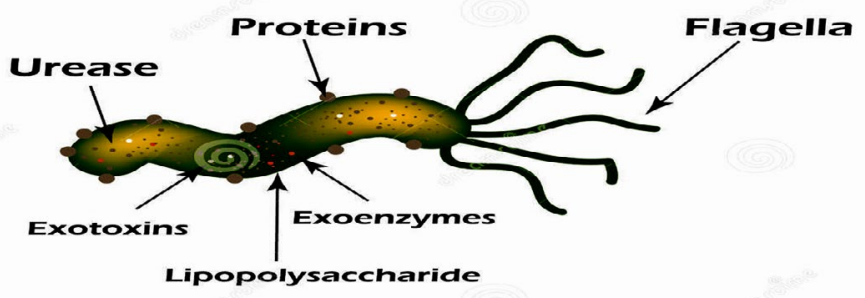

Fig. 1. Immunologic aspects of RHD (Penelope et al.,2009)

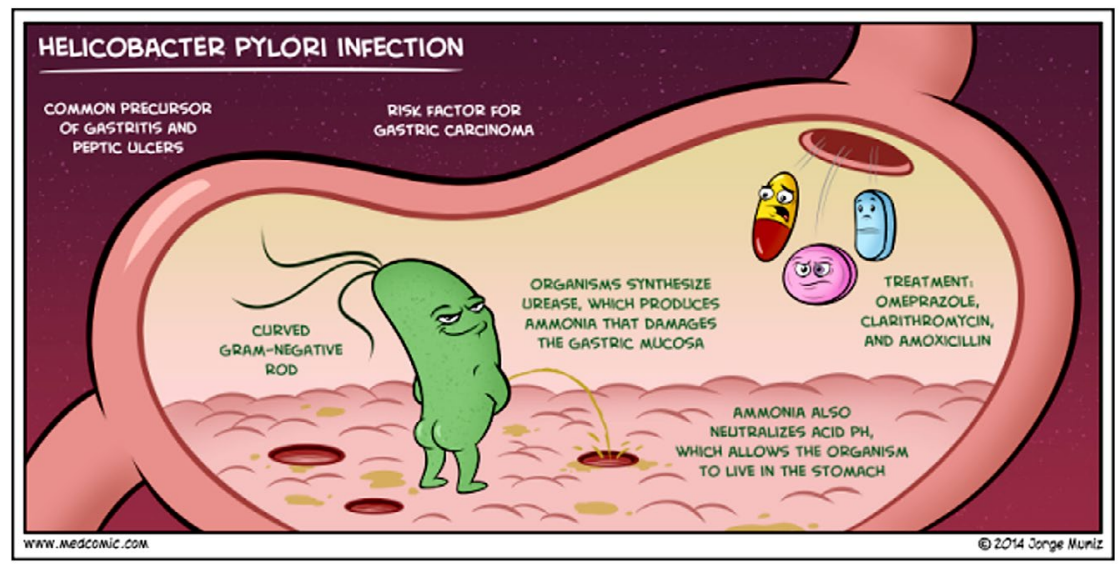

Fig. 2. Structure of H. pylori 

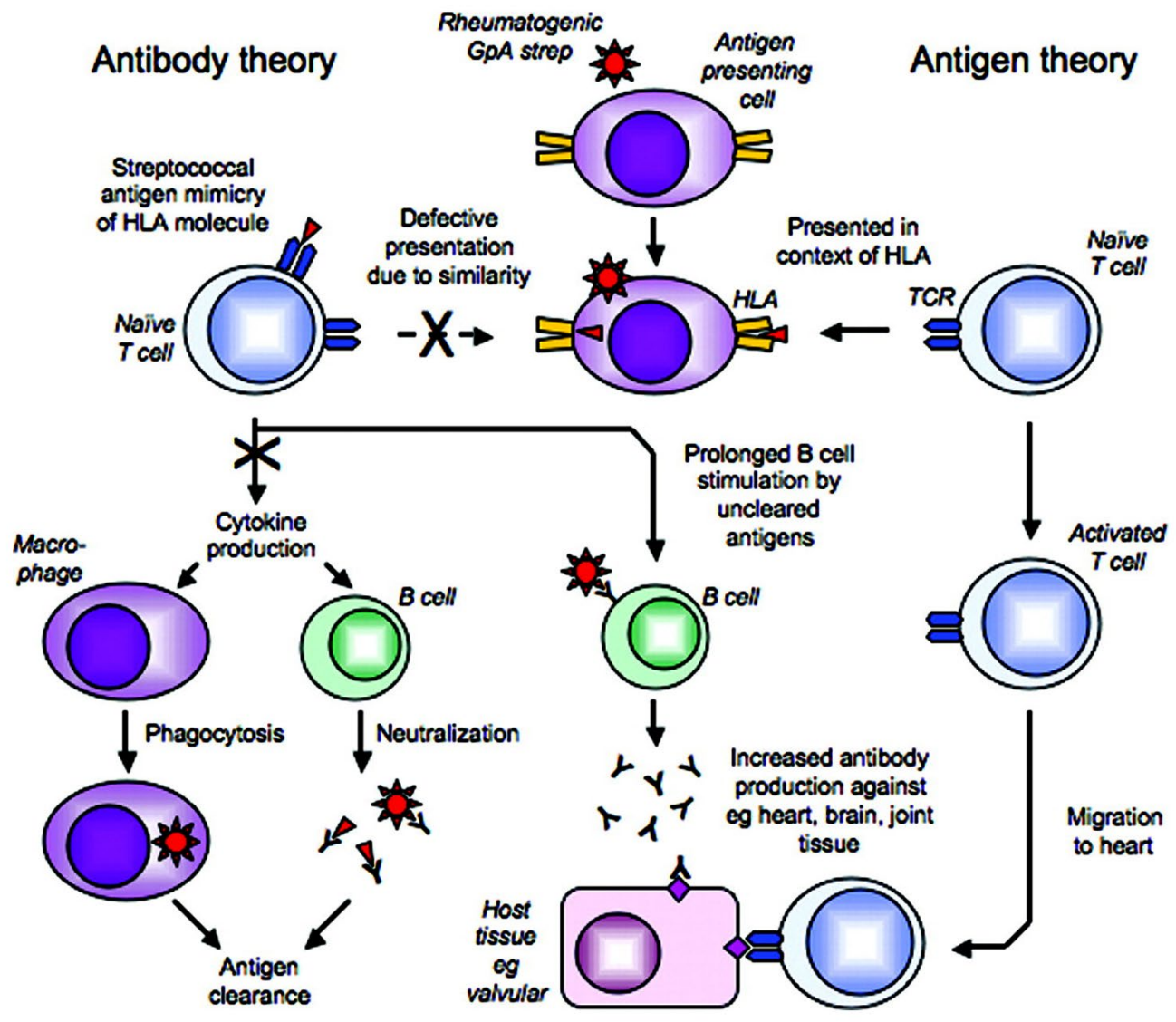

Fig. 3. Main route of $H$. pylori infection

curved bacillus that has an outer membrane and 4 to 8 polar flagella protected by a lipid structure. They produce urease, catalase and cytochrome oxidase. Urease increases the bacterial virulence of $\mathrm{H}$. pylori because it converts urea into $\mathrm{NH}_{3}$ and $\mathrm{H}_{2} \mathrm{O}$, which alkalizes the surrounding acid. Other factors are lipase, adhesins, catalase, plateletactivating factor, CagA and $\operatorname{VacA}^{25}$. Samples for culture obtained from the gastric mucosa. Extragastric samples obtained from dental plaque, rectum, bladder and esophagus. The time required for colony formation varies from four to seven days. Usually, this microorganism is grown in blood serum and antibiotics ${ }^{26}$.

Infection transmission and re-infection

The possible relationship between the expansion of $H$. pylori in three-generation households in a rural Japanese town amongst children and grandparents was investigated ${ }^{27}$.
Based on these results, the spread of $H$. pylori in 3-generation households occurs not only through transmission from mother to infant but also through the route from grandmother to children. Interestingly, having an infected father or grandfather was not a significant indicator of children being associated with the infection. For people infected with $H$. pylori, the spontaneous resolution of infection with new strains has been documented following eradication ${ }^{28}$. The recurrence of infection after eradication for the five years amounted to $48.6 \%$ and new infections in individuals who previously tested negative in the span 10-year period amounted to $38.7 \%{ }^{29}$

Rheumatic heart disease (RHD) is a condition in which the heart valves irreversibly damaged by rheumatic fever (RF). Harm to the valves of the heart can occur immediately after an untreated or under-treated streptococcal infection, 
like a sore throat or scarlet fever. It is a systemic disease of the autoimmune response to group A Streptococcus (GAS) derived from genetically sensitive individuals. The immune response causes an inflammatory disease in the body that can lead to persistent valve damage (fig 1). RHD has an increased risk of complications such as a defect of the heart refers to arrhythmias such as atrial fibrillation, stroke, infective endocarditis and premature death ${ }^{19}$. RHD in children and teenagers around the world is the leading trigger of heart disease. Determination of antibodies to combat the extracellular products of streptococci is of great importance in clinical practice and for the epidemiological study of streptococcal infections and their consequences. The determination of antistreptolysin-O (ASO) can be of great help in the diagnosis because its values reach high values in the presence of important clinical manifestations, decreasing regardless of the subsequent course of the disease. The etiology of most autoimmune diseases is not well defined. Certain factors, including genetics and environmental toxins, can influence or promote autoimmunity ${ }^{30}$.

Inappropriate immune activation that targets autoantigens causes long-lasting 90 pathologies that result in an individual subjected to varying degrees of autoimmune disease. Certain pathogens are thought to be correlated with the pathogenesis of autoimmune diseases. These infectious agents cause autoimmune diseases through various mechanisms. Many bacterial infections have been linked to the development of autoimmune-like responses and constitute a critical clinical problem. Helicobacter pylori (H. Pylori) is a worldwide prevalent pathogenic bacterium that causes gastritis, peptic ulcers and/or gastric malignancies to varying degrees . Because infection with $H$. Pylori is particularly common in developing countries, the infection may be affected by certain health disorders. Therefore, the population status of $H$. pylori infection, particularly in patients suffering from gastrointestinal diseases, should be monitored. $H$. pylori is one of the most popular and widespread bacterial infection ${ }^{31}$. The prevalence rates vary according to public health standards, as infection with $\mathrm{H}$. pylori is more common in "developing countries" compared to "developed countries". $H$. pylori have different strains that are involved in different triggers of infection. The present investigation aimed to investigate the association of $H$. pylori infection and rheumatic heart disease. This might encourage further investigations to include $H$. pylori treatment in the prophylaxis of rheumatic heart disease. Antistreptolysin O (ASO) it is an antibody produced against streptolysin 0 , which is an immunogenic, oxygen-destructive hemolytic toxin produced by streptococci. The most common antibodies produced by the immune system are ASO and anti-DNase group $B$.High levels may demonstrate a previous or 91 current infection. Historically, it was the first bacterial marker to diagnose and monitor RF or scarlet fever. The most common inflammatory indicators used to evaluate patients with suspected septic arthritis, osteomyelitis and RF were CRP and ESR. Serum CRP producing by the liver has already been reported as a reliable marker of oxidative stress and systemic inflammation ${ }^{32}$. The CRP is not only an indicator of the acute phase response that is the main process but can also aggravate existing tissue damage. The concentration of CRP increased during inflammation in the body. It is not a specific test. Erythrocyte sedimentation rate (ESR) is a non-specific indicator of disease activity and most commonly used by physicians to aid in the diagnosis and follow-up of many inflammatory disorders and used ESR levels on a large scale as an indicator of the acute phase response in the immune-inflammatory diseases, including RD. However, the response patterns in the acute phase and the production of cytokines may differ in various inflammatory diseases; acute phase changes mainly reflect the presence and severity of inflammation

\section{ACKNOWLEDGMENTS}

The authors acknowledge with thanks Deanship of Scientific Research (DSR) for technical and financial support.

\section{CONFLICT OF INTEREST}

The authors declare that there is no conflict of interest.

\section{AUTHORS' CONTRIBUTION}

GTA, AA, SB and SS wrote the manuscript. All authors read and approved the manuscript. 


\section{FUNDING}

This project was funded by the Deanship of Scientific Research (DSR), King Abdulaziz University, Jeddah, under grant no. (RG-87-13038).

\section{ETHICS STATEMENT}

Not applicable.

\section{DATA AVAILABILITY}

All datasets generated or analyzed during this study are Included in the manuscript.

\section{REFERENCES}

1. Herrmann J, Volbracht L, Haude M, et al. Biochemical markers of ischemic and non-ischemic myocardial damage. Med Klin. 2001;96: 144-156. doi: 10.1007/ PL00002187

2. Herbrink P, van Doorn LJ. Serological methods for diagnosisof Helicobacter pyloriinfection and monitoring of eradication therapy. Eur J Clin Microbiol Infect Dis. 2000;19:164-173. doi: 10.1007/ s100960050454

3. Heuschmann PU, Neureiter D, Gesslein M, et al. Association between infection with Helicobacter pylori and Chlamydia pneumoniae and risk of ischemic stroke subtypes: results from a population-based case-control study. Stroke. 2001;32:2253-2258. doi: 10.1161/ hs1001.097096

4. Hsu PI, Wu DC, Wu JY, Graham DY. Modified sequential Helicobacter pylori therapy: Proton pump inhibitor and amoxicillin for 14 days with clarithromycin and metronidazole added as a quadruple (hybrid) therapy for the final 7 days. Helicobacter. 2011;16:139-145. doi: 10.1111/j.1523-5378.2011.00828.x

5. Hu Y, Zhu Y, Lu NH. Novel and Effective Therapeutic Regimens for Helicobacter pylori in an Era of Increasing Antibiotic Resistance. Front Cell Infect Microbiol. 2017; 7:168. doi: 10.3389/fcimb.2017.00168

6. Hughes WS. An hypothesis: the dramatic decline in heart attacks in the United States is temporally related to the decline in duodenal ulcer disease and Helicobacter pylori infection. Helicobacter. 2014; 19: 239-241. doi: 10.1111/hel.12123

7. Hunt RH, Xiao SD, Megraud F, et al. World Gastroenterology Organization. Helicobacter pylori in developing countries: World Gastroenterology Organisation Global Guideline. J Gastrointestin Liver Dis. 2011; 20: 299-304.

8. Hurduc V, Plesca D, Dragomir D, Sajin M, Vandenplas Y. A randomized, open trial evaluating the effect of Saccharomyces boulardii on the eradication rate of Helicobacter pylori infection in children. Acta Paediatr. 2009; 98: 127-131. doi: 10.1111/j.16512227.2008.00977.x

9. lerardi E, Giorgio F, lannone A, et al. Noninvasive molecular analysis of Helicobacter pylori: Is it time for tailored first-line therapy? World J Gastroenterol. 2017; 23: 2453-2458. doi: 10.3748/wjg.v23.i14.2453

10. lerardi E, Giorgio F, Losurdo G, Di Leo A, Principi M. How antibiotic resistances could change Helicobacter pylori treatment: A matter of geography? World J Gastroenterol. 2013; 19: 8168-8180. doi: 10.3748/ wjg.v19.i45.8168

11. Ikeda A, Iso H, Sasazuki S, Inoue M, Tsugane S. The combination of Helicobacter pylori- and cytotoxin associated gene-A seropositivity in relation to the risk of myocardial infarction in middle-aged Japanese: The Japan Public Health Center-based study. Atherosclerosis. 2013;230:67-72. doi: 10.1016/j. atherosclerosis.2013.06.013

12. Iman A, Akbar M A, Mohsen KM, et al. Comparison of intradermal injection of autologous epidermal cell suspension vs. spraying of these cells on dermabraded surface of skin of patients with postburn hypopigmentation. Indian J Dermatol. 2013; 58: 240. doi: 10.4103/0019-5154.110844

13. Jackson L, Britton J, Lewis SA, et al. A populationbased epidemiologic study of Helicobacter pylori infection and its association with systemic inflammation. Helicobacter. 2009; 14(5): 108-113. doi: 10.1111/j.1523-5378.2009.00711.x

14. Jacobs-Helber SM, Roh KH, Bailey D, et al. Tumor necrosis factor-alpha expressed constitutively in erythroid cells or induced by erythropoietin has negative and stimulatory roles in normal erythropoiesis and erythroleukemia. Blood. 2003; 101: 524-531. doi: 10.1182/blood-2001-11-0084

15. Jafri W, Yakoob J, Abid S, Sidduqui S, Awan S, Nizami SQ. Helicobacter pylori infection in children: Populationbased age-specific prevalence and risk factors in a developing country. Acta Paediatr. 2010; 99: 279-282. doi: 10.1111/j.1651-2227.2009.01542.x

16. Jaffe AS. Elevations in cardiac troponin measurements: false false-positives. Cardiovasc Toxicol. 2001;1: 87-92. doi: 10.1385/CT:1:2:087

17. Jaine R, Baker M, Venugopal K. Acute rheumatic fever associated with household crowding in a developed country. Pediatr Infect Dis J. 2011;30: 315-319. doi: 10.1097/INF.0b013e3181fbd85b

18. Jeong SY, Kim KJ, Kim DJ, Oh SW, Choi EY. Sandwich ELISA for measurement of cytosolic aspartate aminotransferase in sera from patients with liver diseases. Clin Chem. 2003;49:826-829. doi: 10.1373/49.5.826

19. Kanbay M, Kanbay A, Boyacioglu S. Helicobacter pylori infection as a possible risk factor for respiratory system disease: a review of the literature. Respir Med. 2007; 101: 203-209. doi: 10.1016/j.rmed.2006.04.022

20. Karbasi-Afshar R, Khedmat H, Izadi M. Helicobacter pylori Infection and atherosclerosis: a systematic review. Acta Med Iran. 2015; 53:78-88.

21. Kasper DL, Braunwald E, Fauci H. Harrison's Principles of Internal Medicine. 16th ed. New York: McGraw-Hill. 2004; 1301-486.

22. Kesli R, Gokturk HS, Erbayrak M, Karabagli P, Terzi Y. Comparison of the diagnostic values of the 3 different stool antigen tests for the noninvasive diagnosis of Helicobacter pylori infection. J Investig Med. 2010; 
58: 982-986. doi: 10.2310/JIM.0b013e3181f31569

23. Khabbazi A, Kolahi S, Dastgiri S, et al. Safety of less frequent monitoring of liver transaminases levels in rheumatic patients treated with low-dose methotrexate. Int J Rheum Dis. 2014; 17: 646-652. doi: 10.1111/1756-185X.12416

24. Mahler GJ, Butcher JT. Inflammatory Regulation of Valvular Remodeling: The Good(?), the Bad, and the Ugly. Int J Inflam. 2011;2011:1-14. doi: 10.4061/2011/721419

25. Blum A, Tamir S, Mualem K, Ben-Shushan RS, Keinan-Boker L, Paritsky M. Endothelial dysfunction is reversible in Helicobacter pylori-positive subjects. Am J Med. 2011;124:1171-1174. doi: 10.1016/j. amjmed.2011.08.015

26. Gasbarrini A, Massari I, Serricchio M, et al. Helicobacter pylori eradication ameliorates primary Raynaud's phenomenon. Dig Dis Sci. 1998; 43: 1641-1645. doi: 10.1023/A:1018842527111

27. Csiki Z, Gál I, Sebesi J, Szegedi G. Raynaud syndrome and eradication of Helicobacter pylori. Orv Hetil. 2000; 141: 2827-2829.

28. Aragona $P$, Magazzù $G$, Macchia $G$, et al. Presence of antibodies against Helicobacter pylori and its heat-shock protein 60 in the serum of patients with Sjogren's syndrome. J Rheumatol. 1999; 26: 13061311.
29. Savarino V, Sulli A, Zentilin P, Raffaella MM, Cutolo M. No evidence of an association between Helicobacter pylori infection and Raynaud phenomenon. Scand J Gastroenterol. 2000; 35: 1251-1254. doi: 10.1080/003655200453575

30. Sulli A, Seriolo B, Savarino V, Cutolo M. Lack of correlation between gastric Helicobacter pylori infection and primary or secondary Raynaud's phenomenon in patients with systemic sclerosis. J Rheumatol. 2000; 27: 1820-1821.

31. Hervé $\mathrm{F}$, Cailleux N, Benhamou $\mathrm{Y}$, et al. Helicobacter pylori prevalence in Raynaud's disease. Rev Med Interne. 2006;27:736-741. doi: 10.1016/j. revmed.2006.07.003

32. Danese S, Zoli A, Cremonini F, Gasbarrini A. High prevalence of Helicobacter pylori type I virulent strains in patients with systemic sclerosis. J Rheumatol. 2000; 27: 1568-1569 [PMID: 10852299]

33. Kalabay L, Fekete B, Czirják L, et al. Helicobacter pylori infection in connective tissue disorders is associated with high levels of antibodies to mycobacterial hsp65 but not to human hsp60. Helicobacter. 2002; 7: 250-256 PMID: 12165033 doi: 10.1046/ j.15235378.2002.00092.x

34. Radić M, Kaliterna DM, Bonacin D, Vergles JM, Radić J. Correlation between Helicobacter pylori infection and systemic sclerosis activity. Rheumatology. 2010; 49: 1784-1785 [PMID: 20498013. doi: 10.1093/ rheumatology/keq137 